\title{
Changing the zinc:iron ratio in a cereal-based nutritional supplement has no effect on percent absorption of iron and zinc in Sri Lankan children
}

\author{
Manjula Hettiarachchi ${ }^{1}$, Chandrani Liyanage ${ }^{1}$, David Hilmers ${ }^{2}$, Ian Griffin ${ }^{2}$ and Steven A. Abrams ${ }^{2}$ \\ ${ }^{1}$ Nuclear Medicine Unit, Faculty of Medicine, University of Ruhuna, PO Box 70, Karapitiya, Galle, Sri Lanka \\ ${ }^{2}$ US Department of Agriculture/ARS Children's Nutrition Research Center, Department of Pediatrics, Baylor College of Medicine \\ and Texas Children's Hospital, Houston, TX 77030, USA
}

(Received 24 April 2009 - Revised 16 September 2009 - Accepted 8 October 2009 - First published online 5 November 2009)

The Thriposha programme is a community-level nutrition intervention in Sri Lanka that provides a combination of energy, protein and micronutrients as a 'ready-to-eat' cereal-based food. We measured the bioavailability of Fe and $\mathrm{Zn}$ from Thriposha formula at two different molar ratios of $\mathrm{Zn}: \mathrm{Fe}$ in order to determine the effect on $\mathrm{Fe}$ and $\mathrm{Zn}$ absorption. Children $4-7$ years $(n$ 53) were given a meal prepared with $50 \mathrm{~g}$ Thriposha containing $1.5 \mathrm{mg} \mathrm{Zn}$ as zinc sulphate and either $9 \mathrm{mg}$ (high Fe concentration (HiFe)) or $4.5 \mathrm{mg}$ (low Fe concentration (LoFe)) Fe as ferrous fumarate. $\mathrm{Zn}$ and Fe percent absorption were measured using stable isotopes by tracer:tracee ratio and by incorporation of erythrocytes, respectively. Percent Fe absorption from the two meals was similar $(6.6 \%(4.8) v .4 .8 \%(2.6) ; P=0.15)$, but total Fe absorption was significantly higher from the HiFe meal $(0.59(0.43) \mathrm{mg})$ than the LoFe meal $(0.20(0.12) \mathrm{mg} ; P=0.01)$. There was no significant difference between the two groups in $\mathrm{Zn}$ absorption $(10.7 \%(0.9)$ v. $8.8 \%(1.4), P=0.13$, respectively). Decreasing the amount of Fe in Thriposha did not cause a significant change in the percent absorption of Fe and $\mathrm{Zn}$, but significantly lowered the total amount of absorbed Fe. These results demonstrate the utility of maintaining a higher Fe content in this supplement. Further studies to increase $\mathrm{Zn}$ content are warranted while maintaining a HiFe.

Iron absorption: Zinc absorption: Ready-to-eat cereals

One of the principal objectives of Sri Lanka's healthcare system has been the provision of adequate nutrition to each of its citizens. A key component to achieve this goal has been the Thriposha programme, which was established in 1973 to combat the high prevalence of childhood malnutrition and Fe deficiency anaemia. The Sinhalese word Thriposha means 'triple nutrient' as it provides energy, protein and micronutrients in a precooked 'ready-to-eat' cereal-based food. Although Thriposha has been given to nutritionally vulnerable Sri Lankan children (6-60 months) for over 30 years, its efficacy in lowering the high rates of micronutrient deficiencies has not been evaluated.

All Thriposha is manufactured in a single facility in Sri Lanka. The dry porridge of Thriposha consists of $66.0 \mathrm{~g}$ maize flour, $30.0 \mathrm{~g}$ soya powder, $3.0 \mathrm{~g}$ milk powder and $1.0 \mathrm{~g}$ of a vitamin-mineral premix (vitamin $0.1 \mathrm{~g} /$ mineral $0.9 \mathrm{~g}$ ), which includes $18.0 \mathrm{mg}$ Fe and $3.0 \mathrm{mg} \mathrm{Zn}$ per $100 \mathrm{~g}$. The composition of the mineral-vitamin premix is described in Table 1 . The manufacturing process includes extrusion processing after dehulling the soya. During the extrusion process, degermination of maize takes place when cooking at $130^{\circ} \mathrm{C}$ with steam at a pressure of $60 \mathrm{psi}$. The vitamin-mineral premix is added once the soya-milk blend returns to room temperature and is thoroughly mixed with the remainder of the components. The recommendation is to consume $50 \mathrm{~g}$ Thriposha/child per $\mathrm{d}$ as a meal supplement. A fortified food supplement should ideally provide the RDA of $7 \mathrm{mg}$ (children 1-3 years) to $10 \mathrm{mg}$ (children aged $4-8$ years) elemental $\mathrm{Fe}^{(1)}$. The current Fe content of Thriposha would provide $130 \%$ of the RDA of Fe for children 1-3 years and $90 \%$ for older children, whereas it contains only $35 \%$ of the $\mathrm{Zn}$ requirement at the recommended intake levels. Because Thriposha has a low $\mathrm{Zn}: \mathrm{Fe}$ ratio (1:6) and contains more than the RDA of Fe (18 mg; high Fe concentration (HiFe)), we wanted to evaluate a modified Thriposha formula in which the Fe content was reduced by $50 \%$ in the premix yielding a $\mathrm{Zn}$ :Fe ratio of 1:3 (low Fe concentration (LoFe)). We hypothesised that the modified Thriposha formula ( $\mathrm{LoFe}$ ) would still provide an adequate amount of absorbed $\mathrm{Fe}$, but the percent absorption of $\mathrm{Zn}$ would improve with a lower $\mathrm{Zn}$ :Fe ratio. Therefore, we designed two absorption studies using stable isotopes of $\mathrm{Fe}$ and $\mathrm{Zn}$ to assess their percent absorption at two different ratios from a Thriposha meal.

\section{Experimental methods}

The present study was conducted in accordance with the ethical guidelines specified in the Declaration of Helsinki. All aspects of the investigation involving human subjects were approved by the Ethical Review Committee of the Faculty of Medicine, University of Ruhuna, Sri Lanka, and the Institutional Review Board of Baylor College of Medicine and

Abbreviations: HiFe, high Fe concentration; LoFe, low Fe concentration; CSB, maize soya blend; SF, serum ferritin; TTR, tracer:tracee ratio.

* Corresponding author: Dr Manjula Hettiarachchi, fax +94 91 2222314, email manjula.hettiarachchi@gmail.com 
Table 1. Composition of Thriposha supplement (per $100 \mathrm{~g}$ of supplement)*

\begin{tabular}{|c|c|c|c|}
\hline Vitamin & Amount & Mineral & Amoun \\
\hline Vitamin A (mg) & 0.51 & $\mathrm{Ca}(\mathrm{mg})$ & $900 \cdot 0$ \\
\hline Vitamin D $(\mu \mathrm{g})$ & $2 \cdot 00$ & $P(\mathrm{mg})$ & $670 \cdot 0$ \\
\hline Vitamin E (mg) & 4.41 & $\mathrm{Mg}(\mathrm{mg})$ & 96.0 \\
\hline Vitamin C (mg) & $40 \cdot 0$ & $\mathrm{Fe}(\mathrm{mg})$ & $18 \cdot 0$ \\
\hline Vitamin $B_{6}(\mathrm{mg})$ & $6 \cdot 0$ & $\mathrm{Zn}(\mathrm{mg})$ & 3.0 \\
\hline Vitamin $B_{12}(\mu \mathrm{g})$ & $4 \cdot 0$ & lodine $(\mu \mathrm{g})$ & $44 \cdot 0$ \\
\hline Thiamine $(\mu \mathrm{g})$ & $760 \cdot 0$ & & \\
\hline Riboflavin $(\mu \mathrm{g})$ & $560 \cdot 0$ & & \\
\hline Niacin (mg) & 8.0 & & \\
\hline Folic acid $(\mu \mathrm{g})$ & $200 \cdot 0$ & & \\
\hline Pantothenic acid (mg) & 3.0 & & \\
\hline \multicolumn{4}{|c|}{ Approximate analysis (\% v/w) } \\
\hline Food energy (kJ) & 1.68 & & \\
\hline Fat $(\mathrm{g})$ & $7 \cdot 8$ & & \\
\hline Minerals (g) & $4 \cdot 0$ & & \\
\hline Protein $(\mathrm{g})$ & $20 \cdot 0$ & & \\
\hline Carbohydrate (g) & 61.9 & & \\
\hline Moisture & $6 \cdot 0$ & & \\
\hline
\end{tabular}

* Thriposha contains phytate (inositol hexaphosphate) 121.3 (SD 11.5) mg per $100 \mathrm{~g}$ of dry mix. Thriposha contains $\mathrm{Fe}$ in the form of ferrous fumarate and $\mathrm{Zn}$ in the form of zinc sulphate.

Affiliated Hospitals. Informed written consent was obtained from at least one parent or legal guardian of each study subject. The Fe absorption study (study I) was performed in 2005, and the $\mathrm{Zn}$ absorption study (study II) was accomplished in 2007. The reason that the studies were performed separately was that there was a restriction on the import and export of liquids during the time of the first study. $\mathrm{Zn}$ in liquid form needed to be imported, and urine samples needed to be sent to the United States for analysis. This was accomplished after the restriction was lifted.

For both studies, healthy children aged 4-7 years (an equal proportion of male and female) who had no infectious diseases, respiratory tract infections or diarrhoeal illnesses within the preceding 2 weeks were recruited from the University field training area of the Faculty of Medicine, Galle, through an announcement made to parents 2 weeks before the study. Since the RDA of Fe and $\mathrm{Zn}$ is similar for ages 4 years up to the age of 8 years and dosing and administration of the isotopes in this age group are much easier than for younger children, we recruited children older than 4 years for these studies. Parents were invited to a meeting at which the purpose of the study, risks and benefits were explained in detail, and the opportunity to ask questions was also given. Informed consent was obtained from those parents who agreed to participate. Each child selected was treated with $100 \mathrm{mg}$ mebendazole daily for $3 \mathrm{~d} 2$ weeks before the study in order to eliminate parasites. Next, $3 \mathrm{ml}$ blood was drawn for baseline assessment of $\mathrm{Hb}$, serum ferritin (SF) and serum $\mathrm{Zn}$. Their height, weight and medical history were obtained, and a brief physical examination was performed.

\section{Test meal preparation}

In the preparation of test meals, Thriposha manufactured without added micronutrients (maize soya blend (CSB)) was obtained from the factory. The mineral-vitamin provider
(Asian Chemicals, Colombo, Sri Lanka) provided the mineral-vitamin premix without $\mathrm{Fe}$ and $\mathrm{Zn}$ and supplied ferrous fumarate and zinc sulphate separately in powder form. First, the vitamin-mineral premix (an amount needed to keep the proportion of 1.0 to $99.0 \mathrm{~g}$ of CSB) was mixed with $100 \mathrm{~g}$ from the measured CSB, and then it was mixed with the rest of the CSB using a ribbon blender. The individual portions of $50 \mathrm{~g}$ were then separated. To keep the same molar ratio of $\mathrm{Zn}: \mathrm{Fe}$ (i.e. 1:6) in 50.0 g Thriposha supplement and then to decrease it to $1: 3, \mathrm{Fe}$ in the form of ferrous fumarate or ${ }^{57} \mathrm{Fe}$ (fumarate) and $\mathrm{Zn}$ in the form of zinc sulphate or ${ }^{67} \mathrm{Zn}$ (sulphate) was added to each meal type as described in Table 2. In the preparation of test meals, each subject's meal was individually prepared. Thriposha powder was weighed on a calibrated scale within $\pm 0.1 \mathrm{~g}$ of the desired weight $(50 \mathrm{~g})$ and mixed into a ball with fresh grated coconut $(20 \mathrm{~g})$, sugar $(5 \mathrm{~g})$ and $15 \mathrm{ml}$ distilled water. This is the most common method of preparation used in the local community. Next, the stable isotope doses were spread over the dough according to the type of meal. The exact dose of isotope was carefully measured and recorded with the subject's identification number. The meals were prepared just before administration on each day of testing since Thriposha is a ready-to-eat flour mixture. Each subject was required to eat all of the meal, including crumbs, and the area of the plate containing the meal was rinsed with water and given to the subject to drink. This insured consumption of all the stable isotopes.

\section{Isotope preparation}

${ }^{58} \mathrm{Fe},{ }^{67} \mathrm{Zn}$ and ${ }^{70} \mathrm{Zn}$ were obtained from Trace Sciences International, Toronto, Canada. ${ }^{57} \mathrm{Fe}(>97 \%$ enrichment by mass)-labelled ferrous fumarate was synthesised by $\mathrm{Dr}$ Paul Lohmann GmbH KG, Emmerthal, Germany, in the powder form. ${ }^{58} \mathrm{Fe}$ (96\% enrichment by mass) was provided in elemental metal form, and it was prepared as the sulphate at the Faculty of Medicine, Galle, using the methods described

Table 2. Iron and zinc content in the test meals

\begin{tabular}{|c|c|c|c|c|}
\hline & \multicolumn{2}{|c|}{ Study I } & \multicolumn{2}{|c|}{ Study II } \\
\hline & $\mathrm{HiFe}$ & LoFe & $\mathrm{HiFe}$ & LoFe \\
\hline${ }^{57} \mathrm{Fe}^{\star}(\mathrm{mg})$ & 1.5 & 1.5 & - & - \\
\hline${ }^{67} \mathrm{Zn}+(\mathrm{mg})$ & - & - & 1.5 & 1.5 \\
\hline Elemental Feł (mg) & $7 \cdot 5$ & $3 \cdot 0$ & $9 \cdot 0$ & 4.5 \\
\hline Elemental Zn§ (mg) & 1.5 & 1.5 & - & - \\
\hline Phytate (mg) & $125 \cdot 95$ & $121 \cdot 45$ & $119 \cdot 45$ & 123.45 \\
\hline Zn:Fe ratio\| & $1: 6$ & $1: 3$ & $1: 6$ & $1: 3$ \\
\hline Phytate:Fe molar ratio & $1 \cdot 3: 1$ & $2 \cdot 5: 1$ & $1 \cdot 2: 1$ & $2 \cdot 6: 1$ \\
\hline Phytate:Zn molar ratio** & $8 \cdot 3: 1$ & $8 \cdot 0: 1$ & $7 \cdot 9: 1$ & $8 \cdot 2: 1$ \\
\hline
\end{tabular}

HiFe, high Fe concentration; LoFe, low Fe concentration.

* In the form of ferrous fumarate.

† In the form of zinc sulphate.

$\ddagger$ In the form of ferrous fumarate $(3.042 \mathrm{mg}$ of ferrous fumarate $=1.0 \mathrm{mg}$ of elemental $\mathrm{Fe}$ ).

$\S$ In the form of zinc sulphate $(2.469 \mathrm{mg}$ of zinc sulphate $=1.0 \mathrm{mg}$ of elemental $\mathrm{Zn})$. |l Results expressed in $\mathrm{w} / \mathrm{w}$ of $\mathrm{Zn}$ and $\mathrm{Fe}(\mathrm{w}=$ weight in $\mathrm{mg})$.

I Phyate:Fe molar ratio $=(\mathrm{mg}$ phytate/phytate molar ratio $(660)) /(\mathrm{mg} \mathrm{Fe} / \mathrm{Fe}$ molecular weight $(55 \cdot 8))$.

** Phytate: $\mathrm{Zn}$ molar ratio $=(\mathrm{mg}$ phytate/phytate molecular weight $(660)) /(\mathrm{mg} \mathrm{Zn/Zn}$ molecular weight (65.4)). 
by Kastenmayer et al. ${ }^{(2)}$, and stored as unit doses of $1.5 \mathrm{mg}$ at a concentration of $0.6 \mathrm{mg}$ elemental $\mathrm{Fe} / \mathrm{ml}$.

The ${ }^{67} \mathrm{Zn}$ (90\% enrichment by mass) was obtained as zinc oxide powder, and it was dried at $500^{\circ} \mathrm{C}$ for $30 \mathrm{~min}$ in a muffle furnace. After cooling, the final product was resuspended in $1 \mathrm{M} \mathrm{H}_{2} \mathrm{SO}_{4}$ at $1.0 \mathrm{ml}$ for every $\mathrm{mg}$ of $\mathrm{Zn}$. The final solution supplied a unit dose of $1.5 \mathrm{mg}$ elemental $\mathrm{Zn}$ at a concentration of $1 \mathrm{mg} / \mathrm{ml} .{ }^{70} \mathrm{Zn}$ (90\% enrichment by mass) was prepared in an aqueous solution of $0.085 \mathrm{mg}$ per $\mathrm{ml}$ as zinc chloride at the Investigational Pharmacy of Texas Children's Hospital, Houston, TX, and then tested for sterility and pyrogenicity before use.

\section{Study I - iron absorption}

On day 1 of the feeding trial, the children ( $n$ 30) were invited to the Nuclear Medicine Unit of the Faculty of Medicine, Galle, at 07.00 hours after fasting overnight (except for water). They were given $1.5 \mathrm{mg}$ ferrous sulphate (Fe as ${ }^{58} \mathrm{Fe}$ ) and $50 \mathrm{mg}$ ascorbic acid orally in $200 \mathrm{ml}$ orange juice as a reference dose and were served a meal $2 \mathrm{~h}$ later. The following day they returned after an overnight fast and were served a locally prepared test meal consisting of Thriposha for breakfast. The meal contained, as ferrous fumarate, either $9 \mathrm{mg}$ supplemental $\mathrm{Fe}$ (HiFe, Zn:Fe ratio 1:6) or $4.5 \mathrm{mg}$ supplemental $\mathrm{Fe}$ (LoFe, Zn:Fe ratio 1:3) of which $1.5 \mathrm{mg}$ was ${ }^{57} \mathrm{Fe}$ as ferrous fumarate. Each group consisted of fifteen subjects. They were not allowed to eat or drink (except for water) for $2 \mathrm{~h}$ post-test. One subject in the HiFe group vomited her meal and was therefore excluded from the study. Fifteen days later, $3 \mathrm{ml}$ blood was drawn, and red cells were separated for $\mathrm{Fe}$ isotope analysis.

\section{Study II - zinc absorption}

On the feeding trial day, the children ( $n$ 24) were invited to the Nuclear Medicine Unit of the Faculty of Medicine, Galle, at 07.00 hours after fasting overnight (except for water). All enrolled subjects arrived, and they were served the test meal consisting of Thriposha, as either HiFe or LoFe. No labelled ferrous fumarate was included, but $1.5 \mathrm{mg}$ ${ }^{67} \mathrm{Zn}$ as zinc sulphate was added so that $\mathrm{Zn}$ absorption could be measured. They fasted for an additional $2 \mathrm{~h}$ and then a solution containing $0 \cdot 5 \mathrm{mg}{ }^{70} \mathrm{Zn}$ was given intravenously to each individual in order to calculate $\mathrm{Zn}$ absorption. The $\mathrm{Zn}: \mathrm{Fe}$ ratios in the two meals were the same as in study 1 . Subjects were assigned to receive either the HiFe meal ( $n$ 13) or LoFe meal ( $n$ 11) randomly. Two days later, a $15 \mathrm{ml}$ sample of early morning urine was collected for $\mathrm{Zn}$ isotope analysis.

\section{Sample preparation and analysis}

$\mathrm{Zn}$ was purified from the urine sample using ion exchange chromatography. Isotope enrichments were measured by magnetic sector thermal ionisation MS. Isotope ratios were expressed with respect to the non-administered isotope, $\mathrm{Zn}-66$, and corrected for differences in fractionation using the $\mathrm{Zn}-68: \mathrm{Zn}-66$ ratio $^{(3)}$. The tracer:tracee ratio (TTR) was calculated mathematically from the Zn-67:Zn-66 and $\mathrm{Zn}-70: \mathrm{Zn}-66$ ratios in the sample.
Fe absorption was calculated from incorporation of ${ }^{58} \mathrm{Fe}$ and ${ }^{57} \mathrm{Fe}$ into erythrocytes. Isotope ratios were also measured by thermal ionisation magnetic sector MS (Finnigan MAT 261, Bremen, Germany) ${ }^{(4)}$. Ratios were expressed relative to the non-administered isotope, ${ }^{56} \mathrm{Fe}$, and corrected for temperature-specific differences in fractionation using the ratio of ${ }^{54} \mathrm{Fe}$ to ${ }^{56} \mathrm{Fe}$. Fe isotope ratios were converted to $\mathrm{TTR}^{(5)}$ from the ${ }^{58} \mathrm{Fe} / \mathrm{Fe}$ and ${ }^{57} \mathrm{Fe} /{ }^{56} \mathrm{Fe}$ ratios, as described earlier for $\mathrm{Zn}$.

$\mathrm{Hb}$ concentration was measured spectrophotometrically by the cyanmethaemoglobin method at the Nutrition Research Laboratory, Faculty of Medicine. SF was measured by immunoradiometric assay at the Radioimmunoassay Laboratory of the Nuclear Medicine Unit, with provision of reagents from North East Thames Regional Immunoassay Center, London. Serum $\mathrm{Zn}$ was determined by flame atomic absorption spectrophotometry at the Industrial Technology Institute, Colombo ${ }^{(6)}$. The phytate levels in Thriposha were determined by HPLC using a method described previously ${ }^{(7)}$. Anaemia was defined as $\mathrm{Hb}$ concentration $<115.0 \mathrm{~g} / \mathrm{l}^{(8)}$, Fe deficiency as $\mathrm{SF}$ $<15.0 \mu \mathrm{g} / \mathrm{l}^{(9)}$ and $\mathrm{Zn}$ deficiency as serum $\mathrm{Zn}$ concentration $<9.945 \mu \mathrm{mol} / \mathrm{l}^{(10)}$

\section{Zinc and iron absorption measurements}

$\mathrm{Zn}$ and $\mathrm{Fe}$ absorption were measured as previously described $^{(5,11)}$. Briefly, $\mathrm{Zn}$ absorption was calculated from the fractional excretion of the oral and intravenous isotope in the $48 \mathrm{~h}$ urine sample from the equation:

\section{Zn absorption $=$}

TTR of oral isotope/dose of oral isotope $\overline{\text { TTR of intravenous isotope/dose of intravenous isotope }}$

where TTR is the tracer:tracee ratio.

Erythrocyte incorporation of the oral $\mathrm{Fe}$ isotope was given by the equation:

$$
\text { Erythrocyte incorporation }=\text { TTR of isotope } \times \mathrm{Fe}_{\mathrm{Circ}} \text {, }
$$

where $\mathrm{Fe}_{\mathrm{Circ}}$ is the total amount of Fe circulating as $\mathrm{Hb}^{(2,12)}$ and is given by

$$
\begin{aligned}
\mathrm{Fe}_{\text {Circ }}= & (\mathrm{Hb})(\mathrm{g} / \mathrm{dl}) \times \text { blood volume }(65 \mathrm{ml} / \mathrm{kg}) \times \text { weight }(\mathrm{kg}) \\
& \times 3.47 \mathrm{mg} \mathrm{Fe} / \mathrm{g} \text { per } \mathrm{Hb} \times 1 \mathrm{dl} / 100 \mathrm{ml} .
\end{aligned}
$$

Fe absorption was then estimated by assuming that $90 \%$ of absorbed $\mathrm{Fe}$ was incorporated into erythrocytes.

\section{Statistical analysis}

Power calculations were based on the $\mathrm{Zn}$ absorption from fortified rice flour seen in a previous study in a similar population in Galle, Sri Lanka $\left(10.9 \%\right.$, SD 5.1) ${ }^{(13)}$. A study by Peres et al. ${ }^{(14)}$ demonstrated a dose-dependent inhibition of $\mathrm{Zn}$ absorption when combined with Fe. Based on these data, it was assumed that halving the Fe: $\mathrm{Zn}$ ratio would increase $\mathrm{Zn}$ absorption by $2: 3$. A sample size of twelve would therefore give a power of $80 \%$ to detect the difference between the $\mathrm{Zn:Fe} \mathrm{(1:6)} \mathrm{group}$ and the $\mathrm{Zn}: \mathrm{Fe}(1: 3)$ group at $P<0 \cdot 05$. Each group had three additional subjects in order to accommodate dropouts. 
Statistical analysis was carried out using SPSS version 10.0 (SPSS, Inc., San Mateo, CA, USA). The prevalence of undernutrition was assessed on the basis of weight-for-age, heightfor-age and weight-for-height using the Center for Disease Control 1978 reference standards. Descriptive statistics are expressed as the mean (SD). Fe and $\mathrm{Zn}$ absorption from the two meals were compared using a two-sided $t$ test. Fe and $\mathrm{Zn}$ absorption data were also analysed using analysis of covariance with other biomarkers ( $\mathrm{SF}, \mathrm{Hb}$ and serum $\mathrm{Zn}$ ), and reference dose absorption as covariates. The relationship between $\mathrm{Fe}$ absorption and $\mathrm{Fe}$ status as measured by the above parameters was assessed by linear regression analysis. SF concentrations were $\log _{10}$ transformed due to lack of normality. $P$-values less than 0.05 were considered to be significant.

\section{Results}

\section{Iron absorption (study 1)}

There were sixteen male and thirteen female subjects enrolled with ages ranging between 53.0 and 87.0 months. Anthropometric, biochemical and haematological analyses are presented in Table 3. Thirty-four percentage ( $n$ 10) of children were underweight (weight-for-age $z$-scores $<-2.0$ ), six children $(43 \%)$ in the HiFe group and four children $(27 \%)$ in the LoFe group $(P<0.05)$. Only two children $(7.0 \%)$ were stunted (height-for-age $z$-scores $<-2 \cdot 0$ ), and each group had one stunted child. Baseline data from the present study showed that only one subject $(3 \%)$ in the HiFe had anaemia $(\mathrm{Hb}<115.0 \mathrm{~g} / \mathrm{l})$, and none of the children were Fe deficient $(\mathrm{SF}<15 \mu \mathrm{g} / \mathrm{l})$. Four $(14 \%)$ children had low serum $\mathrm{Zn}(<9.945 \mathrm{mmol} / \mathrm{l})$ with two in each group.

Reference dose $\mathrm{Fe}$ absorption $\left({ }^{58} \mathrm{Fe}\right)$ was not significantly different between subjects randomised to receive the $\mathrm{HiFe}$ or LoFe meal (19.2\% (SD 13.4) v. 17.0\% (SD 10.5), $P=0.63$; Table 4). The overall mean percent absorption of ${ }^{57} \mathrm{Fe}$ was $6.6 \%$ (SD 4.8) (HiFe) and $4.8 \%$ (SD 2.6) (LoFe, $P=0.15)$. The percent $\mathrm{Fe}$ absorption ranged from 0.5 to $18.0 \%$ in the
HiFe group with a geometric mean of $4.86 \%$, whereas in the LoFe group it ranged from 0.7 to $10.0 \%$ with a geometric mean of $3.59 \%$. There was no difference in percent Fe absorption between the two meals when $\mathrm{Hb}(P=0 \cdot 23)$, SF $(P=0 \cdot 19)$ or serum $\mathrm{Zn}(P=0 \cdot 18)$ were used as covariates. When normalised to a reference dose absorption of $40 \%$, ferrous fumarate absorption in the two groups was 13.6 and $9.6 \%$. The percent reference dose ${ }^{58} \mathrm{Fe}$ absorption was significantly negatively correlated with SF $(r-0.37 ; P<0.05)$, but the ${ }^{57} \mathrm{Fe}$ absorption did not show a significant correlation $(r-0.21 ; P=0.27)$ with SF. There were no significant correlations in either meal between $\mathrm{Fe}$ absorption and the serum $\mathrm{Zn}$ concentration.

\section{Zinc absorption (study II)}

There were eleven male and thirteen female subjects enrolled in the present study with ages ranging from 52.0 to $78 \cdot 0$ months. The anthropometric and basic biochemical analyses are found in Table 3 . Seventeen percentage of the children (n 4) were underweight, but only one of these children $(8 \%)$ was in the HiFe group whereas three children $(27 \%)$ were in the LoFe group. None of the children were stunted in these groups. There were no significant differences between the groups in terms of age, anthropometrics and biochemical data. Baseline data showed that five $(21 \%)$ of the subjects were anaemic, three children $(23 \%)$ in the HiFe group and two children $(18 \%)$ in the LoFe group. None of the children were $\mathrm{Fe}$ deficient. Low serum $\mathrm{Zn}$ concentrations were seen in nine children (38\%), four children $(31 \%)$ in the $\mathrm{HiFe}$ group and five children $(46 \%)$ in the LoFe.

There were no differences between the two groups in the percent $\mathrm{Zn}$ absorption from the meal (10.7\% (SD 3.3) $v$. $8.8 \%$ (SD 4.6), $P=0.13$; Table 4). The $\mathrm{Zn}$ absorption levels ranged from 5.7 to $15.9 \%$ in the HiFe group with a geometric mean of $10.2 \%$, whereas in the LoFe group, it ranged from 5.6 to $15.7 \%$ with a geometric mean of $7.7 \%$. There was no difference in percent $\mathrm{Zn}$ absorption between the two meals when $\mathrm{Hb}(P=0 \cdot 28)$, serum $\mathrm{Zn}(P=0 \cdot 16)$ or $\mathrm{SF}(P=0 \cdot 27)$ were used as covariates. $\mathrm{Zn}$ absorption was positively

Table 3. Baseline anthropometry and biochemical values of study subjects* (Mean values and standard deviations)

\begin{tabular}{|c|c|c|c|c|c|c|c|c|}
\hline & \multicolumn{4}{|c|}{ Study I } & \multicolumn{4}{|c|}{ Study II } \\
\hline & \multicolumn{2}{|r|}{$\mathrm{HiFe}$} & \multicolumn{2}{|r|}{ LoFe } & \multicolumn{2}{|r|}{$\mathrm{HiFe}$} & \multicolumn{2}{|r|}{ LoFe } \\
\hline & Mean & $S D$ & Mean & SD & Mean & $S D$ & Mean & $S D$ \\
\hline Age (months) & $73 \cdot 2$ & 8.9 & $77 \cdot 6$ & $7 \cdot 5$ & $60 \cdot 4$ & $9 \cdot 0$ & $58 \cdot 9$ & $10 \cdot 3$ \\
\hline Wt $(\mathrm{kg})$ & $17 \cdot 38$ & $3 \cdot 3$ & $18 \cdot 42$ & $3 \cdot 4$ & $16 \cdot 07$ & 2.5 & $15 \cdot 41$ & $1 \cdot 8$ \\
\hline $\mathrm{Ht}(\mathrm{cm})$ & $112 \cdot 61$ & $6 \cdot 4$ & $115 \cdot 19$ & $7 \cdot 5$ & $107 \cdot 34$ & $6 \cdot 8$ & $107 \cdot 00$ & $5 \cdot 2$ \\
\hline BMI $\left(\mathrm{kg} / \mathrm{m}^{2}\right)$ & 13.62 & 1.7 & 13.79 & 1.4 & $13 \cdot 86$ & 0.9 & 13.46 & $1 \cdot 3$ \\
\hline WAZ & -1.58 & $1 \cdot 3$ & -1.43 & $1 \cdot 2$ & $-1 \cdot 10$ & 0.8 & $-1 \cdot 27$ & 1.0 \\
\hline HAZ & -0.61 & 0.9 & -0.59 & 1.0 & -0.42 & 0.6 & -0.24 & $1 \cdot 2$ \\
\hline WHZ & $-1 \cdot 29$ & $1 \cdot 2$ & $-1 \cdot 27$ & 0.9 & $-1 \cdot 11$ & 0.7 & -1.40 & 0.9 \\
\hline $\mathrm{Hb}(\mathrm{g} / \mathrm{l})$ & $120 \cdot 71$ & $10 \cdot 4$ & $124 \cdot 27$ & $7 \cdot 0$ & $119 \cdot 08$ & $8 \cdot 4$ & $120 \cdot 10$ & 9.9 \\
\hline \multirow[t]{2}{*}{ Serum Zn $(\mu \mathrm{mol} / \mathrm{l})$} & $11 \cdot 44$ & 3.3 & $11 \cdot 78$ & 1.3 & 11.69 & $3 \cdot 1$ & $11 \cdot 37$ & $3 \cdot 2$ \\
\hline & Median & Interquartile range & Median & Interquartile range & Median & Interquartile range & Median & Interquartile range \\
\hline $\mathrm{SF}(\mu \mathrm{g} / \mathrm{l})$ & $27 \cdot 88$ & $20 \cdot 6 ; 35.5$ & 30.06 & $22 \cdot 0 ; 46.4$ & 25.97 & $19 \cdot 3 ; 34.5$ & $27 \cdot 90$ & $22 \cdot 0 ; 35.6$ \\
\hline$n$ (Male, female) & & $14(7,7)$ & & $15(8,7)$ & & $13(6,7)$ & & $11(5,6)$ \\
\hline
\end{tabular}

HiFe, high Fe concentration; LoFe, low Fe concentration; WAZ, weight-for-age z-score; HAZ, height-for-age $z$-score; WHZ, weight-for-height $z$-score; SF, serum ferritin. ${ }^{*}$ All $z$-scores derived from the Center for Disease Control 1978 reference standards. 
Table 4. Absorption of Fe and $\mathrm{Zn}$ from the HiFe and $\mathrm{LoFe}^{\star}$

\begin{tabular}{|c|c|c|c|c|c|c|}
\hline & \multicolumn{6}{|c|}{ Absorption (\%) } \\
\hline & \multicolumn{2}{|c|}{${ }^{57} \mathrm{Fe}$} & \multicolumn{2}{|c|}{${ }^{58} \mathrm{Fe}$} & \multicolumn{2}{|c|}{$\mathrm{Zn}$} \\
\hline & Mean & SD & Mean & SD & Mean & SD \\
\hline \multicolumn{7}{|l|}{ Study I } \\
\hline HiFe & $6 \cdot 56$ & $4 \cdot 8$ & $19 \cdot 23$ & 13.4 & & \\
\hline LoFe & $4.77 \%$ & $2.6 \%$ & $17.04 \%$ & $10.5 \%$ & & \\
\hline \multicolumn{7}{|l|}{ Study II } \\
\hline HiFe & \multicolumn{2}{|c|}{ - } & \multicolumn{2}{|c|}{ - } & $10 \cdot 71$ & $3 \cdot 3$ \\
\hline LoFe & \multicolumn{2}{|c|}{ - } & \multicolumn{2}{|c|}{-} & 8.84 & 4.6 \\
\hline
\end{tabular}

HiFe, high Fe concentration; LoFe, low Fe concentration.

*There is no significant difference between groups in $\mathrm{Fe}$ reference dose $\left({ }^{58} \mathrm{Fe}\right)$ absorption $(P=0.63)$ or test meal $\mathrm{Fe}\left({ }^{57} \mathrm{Fe}\right)$ absorption $(P=0.15)$ or $\mathrm{Zn}$ absorption $(P=0.13)$

correlated with serum $\mathrm{Zn}$ concentration $(r 0.71 ; P<0.001)$, but there were no significant correlations between $\mathrm{Zn}$ absorption from either meal and SF or $\mathrm{Hb}$ concentrations.

\section{Total absorbed iron and zinc}

Total absorbed $\mathrm{Fe}$ based on the quantity of $\mathrm{Fe}$ in the HiFe meal and the calculated percent absorption were 0.59 (SD 0.43 ) mg; similarly, total absorbed $\mathrm{Zn}$ was 0.16 (SD 0.05 ) $\mathrm{mg}$. This was calculated by multiplying the percent absorption of each mineral by the $\mathrm{Fe}$ or $\mathrm{Zn}$ content in the meal. These amounts represent 65 and $13 \%$ of the estimated absorbed requirement of $\mathrm{Fe}(0.9 \mathrm{mg})$ and $\mathrm{Zn}(1.2 \mathrm{mg})^{(1)}$, respectively, for the age group studied. With the modified meal (LoFe), only $0.20 \quad$ (SD 0.12$) \mathrm{mg} \quad \mathrm{Fe}$ and 0.13 (SD 0.07 ) $\mathrm{mg} \mathrm{Zn}$ were absorbed. This would provide $22 \%$ of the estimated absorbed requirement of $\mathrm{Fe}$ and $11 \%$ of $\mathrm{Zn}$ in this age group.

\section{Phytate levels in Thriposha meal}

The phytate levels in a CSB sample of each meal type were analysed, and the results were presented in Table 2 . The mean level was 121.3 (SD 11.5) $\mathrm{mg}$ phytate per $100 \mathrm{~g}$ of dry mix. Therefore, the HiFe meals had a 1.2:1 molar ratio of phytate:Fe and LoFe meals had a ratio of 2.5:1. Phytate:Zn molar ratio was $8 \cdot 0: 1$ in both types of meals.

\section{Discussion}

The objectives of the present study were to determine the extent to which $\mathrm{Fe}$ and $\mathrm{Zn}$ are absorbed by young children when given a maize flour-based, pre-cooked formula as part of a national strategy to improve nutrition and to ascertain the total absorbed $\mathrm{Fe}$ and $\mathrm{Zn}$ at different molar ratios. Nearly, all the study population consisted of non-anaemic young children (only one child in study I was anaemic), and all appeared to have adequate $\mathrm{Fe}$ stores. However, thirteen children from both studies $(26 \%)$ were deficient in $\mathrm{Zn}$ (serum $\mathrm{Zn}<9.945 \mu \mathrm{mol} / \mathrm{l}$ ). While the fractional absorption of $\mathrm{Fe}$ and $\mathrm{Zn}$ was not significantly different at the two ratios studied, the total absorbed $\mathrm{Fe}$ was higher from the meal with the higher Fe content. Modifying the Thriposha product to contain less Fe should, therefore, be avoided as it reduced the total absorbed Fe content without improving fractional Zn absorption.

There are few studies that have reported the bioavailability of Fe from ferrous fumarate. A trial by Davidsson et al. ${ }^{(15)}$ in 6-12-month formula-fed infants demonstrated a fractional absorption of $4.1 \%$ from $2.5 \mathrm{mg}$ labelled ferrous fumarate in a wheat and soya infant cereal. A second study by Davidsson et al. ${ }^{(16)}$ reported fractional $\mathrm{Fe}$ absorption of $5.5-6 \cdot 2 \%$ in Guatemalan females aged 12-13 years fed a meal based on maize tortillas and black bean paste fortified with labelled ferrous fumarate. A study done in Ghana by Tondeur et al. ${ }^{(17)}$ with infants 6-18 months demonstrated fractional $\mathrm{Fe}$ absorption from labelled ferrous fumarate sprinkles of $4.48 \%$ in Fe-deficient infants, $4.65 \%$ in Fe-replete infants and $8.25 \%$ in those with $\mathrm{Fe}$ deficiency anaemia. Although the age range of our subjects was different, these results appear to be consistent with the present findings (mean fractional absorption from fumarate of 6.6 and $4.8 \%$ and geometric means of 4.9 and $3.6 \%$ ).

Complementary food diets in developing countries are often low in bioavailable Fe, as described by Lutter \& Rivera ${ }^{(18)}$. This is due to the low Fe content of the diet and the poor bioavailability of the $\mathrm{Fe}$ from meals. Many cereal-based complementary foods are not good sources of Fe because of their high phytate content ${ }^{(19)}$. The LoFe meal had a higher phytate:Fe molar ratio $(2 \cdot 5: 1)$, which may partially explain the lower fractional absorption from that meal.

Previous studies using higher doses of Fe have analysed the effect of $\mathrm{Zn}$ on fractional $\mathrm{Fe}$ absorption, but the results have been inconclusive. Crofton et al. ${ }^{(20)}$, using the Fe post-absorptive plasma curve as a surrogate measure of Fe absorption, found a reduction in fractional $\mathrm{Fe}$ absorption from a water solution containing $27.5 \mathrm{mg} \mathrm{Zn}$ and $23.5 \mathrm{mg}$ Fe (Zn:Fe molar ratio 1:1). However, no effect on fractional Fe bioavailability was found in pregnant women receiving a prenatal supplement containing $60 \mathrm{mg} \mathrm{Fe}$ and $15 \mathrm{mg} \mathrm{Zn}^{(21)}$. Rossander-Hulten et al. ${ }^{(22)}$ reported that a fivefold excess of $\mathrm{Zn}: \mathrm{Fe}$ administered in water reduced fractional $\mathrm{Fe}$ absorption by $56 \%$ among adults aged 19-50 years and that the effect disappeared when $\mathrm{Zn}: \mathrm{Fe}$ in the same ratio was administered in a hamburger meal in a separate group of adults. When Friel et al. ${ }^{(23)}$ administered $1200 \mu \mathrm{g} / \mathrm{kg}$ Zn with $300 \mu \mathrm{g} / \mathrm{kg}$ Fe between feedings, it resulted in an inhibition of erythrocyte incorporation of $\mathrm{Fe}$ in premature infants. The same relative ratio of $\mathrm{Zn}: \mathrm{Fe}$ administered with feedings did not inhibit erythrocyte incorporation of $\mathrm{Fe}$.

The observed low $\mathrm{Zn}$ fractional absorption in either meal can be attributed to the phytate content in the food as described by Chiplonkar \& Agte ${ }^{(24)}$. This group had extensively studied the effects of phytate and folic acid on $\mathrm{Zn}$ fractional absorption and developed a statistical model for predicting $\mathrm{Zn}$ bioavailability from cereal-based diets. Estimates of dietary $\mathrm{Zn}$ absorption as developed by WHO have been stated as 50, 30 and $15 \%$ for diets having phytate: $\mathrm{Zn}$ molar ratio $<5: 1,5-15: 1$ and $>15: 1$, respectively ${ }^{(25)}$. However, the average phytate: $\mathrm{Zn}$ molar ratio was $11: 1$ in the study by Chiplonkar \& Agte $^{(24)}$, and an average Zn absorption of $16.8 \%$ was reported. Thriposha had a measured phytate: $\mathrm{Zn}$ molar ratio of $8 \cdot 0: 1$; however, the percent $\mathrm{Zn}$ absorption was only 10.7 and $8.8 \%$ in the two groups studied, demonstrating values somewhat lower than predicted by the present model. 
Micronutrients such as $\mathrm{Fe}, \mathrm{Ca}$, folic acid, riboflavin and niacin have been shown to affect the bioavailability of $\mathrm{Zn}^{(24)}$. Fortification with mineral salts has the potential to reduce the bioavailability of other minerals in the food by either changing their intestinal solubility or by competing for uptake at absorption sites, as noted by Abrams \& Atkinson $^{(26)}$. Data for such mineral-mineral interactions come primarily from studies of single mineral dietary supplements rather than micronutrients used as fortificants in foods. Concern has primarily centred on the effect of $\mathrm{Ca}$ and $\mathrm{P}$ fortification on $\mathrm{Fe}$ and $\mathrm{Zn}$ absorption, $\mathrm{Zn}$ fortification on copper absorption and Fe fortification on $\mathrm{Zn}$ absorption. However, several studies have shown that neither $\mathrm{Fe}$ absorption nor Fe stores are affected when infants are fed $\mathrm{Ca}$ - and P-fortified formulas ${ }^{(27)}$ or when children are fed a Ca-fortified breakfast cereal ${ }^{(28)}$. Data are not available to support recommendations on optimal dietary Ca:Zn ratios ${ }^{(26)}$.

We noted a significant inverse relationship between reference dose percent Fe absorption when given with orange juice (containing ascorbic acid that enhances absorption) and SF. This is in contrast to an earlier study where Fe absorption from orange juice (with ascorbic acid) was not related to $\mathrm{SF}$, but percent $\mathrm{Fe}$ absorption from apple juice (without ascorbic acid) was inversely related to $\mathrm{SF}^{(29)}$. We also found a negative relationship between percent $\mathrm{Fe}$ absorption from the meal and SF concentrations of the subjects, but this did not reach a level of significance $(r-0 \cdot 21 ; P=0 \cdot 27)$. Similar significant inverse relationships between $\mathrm{Fe}$ absorption from the diet and SF have been reported ${ }^{(30,31)}$. Interestingly, we saw a significant positive correlation in serum $\mathrm{Zn}$ concentration $v$. percent $\mathrm{Zn}$ absorption from the meal. The present finding was not reported previously and merits further research, although serum $\mathrm{Zn}$ may not be a reliable indicator of body $\mathrm{Zn}$ stores. Adequate $\mathrm{Zn}$ stores help to maintain antioxidant capacity. One animal study demonstrated that $\mathrm{Zn}$ deficiency impairs intestinal antioxidant capacity by lowering the expression of metallothionein, an effective scavenger of hydroxyl radicals that can play a major role in the development of oxidative damage ${ }^{(32)}$. Furthermore, increased localisation of metallothionein in the intestinal mucosa during $\mathrm{Zn}$ repletion among rats was seen. $\mathrm{Zn}$ per se can reduce $\mathrm{Fe}$ mediated production of hydroxyl radicals and thereby protect against oxidative stress ${ }^{(33)}$. Hence, we speculate that improved $\mathrm{Zn}$ status may lead to higher $\mathrm{Zn}$ levels in the serum and enhanced intestinal non-enzymatic antioxidant capacity and functional integrity of the mucosa. It is possible that this could lead to increased percent $\mathrm{Zn}$ absorption from the meal.

We compared the present mineral and vitamin composition of Thriposha with the proposed nutrient composition in fortified complementary foods described by Lutter \& Dewey ${ }^{(34)}$, and noted that levels of some minerals and vitamins are not consistent with their guidelines. However, their studies focused principally on toddlers up to the age of 2 years; whereas, Thriposha has been formulated for older children as well. Recent WHO guidelines on fortification state that the goal of fortification should be to provide approximately $97.5 \%$ of the individuals in a population with an intake that meets their estimated absorbed requirement for specific micronutrients without exceeding their tolerable upper intake levels ${ }^{(35)}$. This is more realistic and safer than attempting to meet the recommended intake for the entire population ${ }^{(36)}$.
The estimated absorbed requirement values for $\mathrm{Fe}$ and $\mathrm{Zn}$ are $4.5 \mathrm{mg} / \mathrm{d}^{(37)}$ for this age group. We found a satisfactory total absorbed $\mathrm{Fe}$ content from Thriposha without hindering fractional $\mathrm{Zn}$ absorption. It would be useful to evaluate $\mathrm{Fe}$ absorption in Thriposha with twice the concentration of $\mathrm{Zn}$ (3.0 mg per $100 \mathrm{~g}$ Thriposha) while maintaining the same amount of $\mathrm{Fe}(18.0 \mathrm{mg})$ in order to optimise total absorption of $\mathrm{Fe}$ and $\mathrm{Zn}$. In a population at high risk for severe $\mathrm{Zn}$ deficiency $^{(38)}$, increasing $\mathrm{Zn}$ content and maintaining the same Fe content may be justified.

We had in fact planned to perform both the $\mathrm{Fe}$ and $\mathrm{Zn}$ absorption studies at the same time and with the same subjects. Unfortunately, for logistic reasons, we had to complete the study with two different groups 1 year apart. This was a limitation in the study, and certainly alternative study designs could have been chosen if this constraint had been foreseen. Secondly, the fasting status of the children could have had an impact on the $\mathrm{Zn}$ absorption results. However, we insured close supervision of the subjects, and the difference in fasting duration between subjects varied only between 10 and $11 \mathrm{~h}$. The present study used state of the art laboratory and clinical techniques to obtain the most accurate measurements possible under these conditions. We collected only a single spot urine collection at $2 \mathrm{~d}$ after isotope dosing to assess $\mathrm{Zn}$ absorption, which we believe is adequate for this purpose. Sparacino et al. ${ }^{(39)}$ have shown that this is mathematically equivalent to measuring the isotopes in a single serum sample. As such, it slightly underestimated true $\mathrm{Zn}$ absorption. However, the degree of underestimation is affected very little by delaying the urine collection for $2-5 \mathrm{~d}$ longer, and doing so results in much lower isotope enrichment in the sample and much increased measurement error. We believe that a urine collection between 2 and $3 \mathrm{~d}$ after isotope administrations provides a good balance between approximation of the theoretical true $\mathrm{Zn}$ absorption and the practical need to ensure sufficient isotopic enrichment.

Based on the present findings, we do not recommend a change in the Fe content of the current Thriposha formula (i.e. HiFe meal) since it provides $65 \%$ of the daily total absorbed Fe requirement for this age group with each $50 \mathrm{~g} / \mathrm{d}$ of supplement. However, a lower percentage (approximately $10 \%$ ) of the total absorbed $\mathrm{Zn}$ requirement was met. Lowering the $\mathrm{Fe}$ content did not improve either fractional $\mathrm{Fe}$ or $\mathrm{Zn}$ absorption. The $\mathrm{Zn}$ content or $\mathrm{Zn}$ bioavailability of Thriposha should be improved to enhance $\mathrm{Zn}$ absorption from the product. An intervention that should be evaluated is the effect on total absorbed Fe and $\mathrm{Zn}$ with an increase in the $\mathrm{Zn}$ content of Thriposha while maintaining the current Fe level.

\section{Conclusions}

We have shown that reducing the $\mathrm{Zn}$ :Fe ratio from 1:6 to $1: 3$ by lowering total Fe content in a cereal-based fortified food product did not significantly change the percent Fe absorption, although it significantly lowered the total absorbed Fe. The current Thriposha formula provided approximately $65 \%$ of the daily absorbed Fe requirement. The modified ratio also did not significantly affect the total absorbed $\mathrm{Zn}$ or the percent absorption of $\mathrm{Zn}$. In analysing absorbed micronutrients in food programmes such as Thriposha, it is important to examine total absorption as well as fractional absorption. These results 
demonstrate the utility of maintaining a higher Fe content in nutritional supplements such as Thriposha. Further studies to increase $\mathrm{Zn}$ content while maintaining a higher Fe intake are warranted.

\section{Acknowledgements}

The Thriposha supplement was received from the factory as maize soya blend premix free of charge through the coordinating officer in charge for the Thriposha programme, Nutrition Division of the Medical Research Institute, Colombo. The mineral/vitamin premix was supplied free of charge by Asian Chemicals Ltd, Colombo. The present project was sponsored with funds provided by the International Atomic Energy Agency (IAEA contract SRL - 11958). There is no conflict of interest among authors. Contributors: M. H. was responsible for the research project and involved in all aspects including designing, sample selection, data collection, sample analysis, results and statistical analysis, and paper writing. C. L. was responsible for the research project and involved in concept designing, supervision of sample selection, paper writing and editing. D. H., I. G. and S. A. A. were responsible for the research project and were involved in designing the sample size, statistical analysis, isotope analysis and editing the paper.

\section{References}

1. Institute of Medicine (2001) DRI (Dietary Reference Intake). Washington, DC: National Academy Press.

2. Kastenmayer P, Davidsson L, Galan P, et al. (1994) A double stable isotope technique for measuring iron absorption in infants. Br J Nutr 71, 411-424.

3. Griffin IJ, King JC \& Abrams SA (2000) Body weight-specific zinc compartmental masses in girls significantly exceed those reported in adults: a stable isotope study using a kinetic model. J Nutr 130, 2607-2612.

4. Ames SK, Gorham BM \& Abrams SA (1999) Effects of high compared with low calcium intake on calcium absorption and incorporation of iron by red blood cells in small children. Am $J$ Clin Nutr 70, 44-48.

5. Cobelli C, Toffolo G \& Foster DM (1992) Tracer-to-tracee ratio analysis of stable isotope date: link with radioactive formalism. Am J Physiology 262, E968-E975.

6. Determination of lithium, zinc and copper in blood serum by flame micro sampling (Online) (August 1981) Varian Instrument at work, Number AA-11 http://www.varianinc.com/ image/vimage/docs/products/spectr/aa/atworks/aa016.pdf (accessed 20 July 2003).

7. Sandberg AS \& Ahderinne R (1986) HPLC method for determination of inositol tri-, tetra-, penta-, and hexaphosphates in foods and intestinal contents. J Food Sci 51, 547-550.

8. World Health Organization (1994) Indicators and Strategies for Iron Deficiency and Anemia Programmes. Report of the WHO/UNICEF/UNU Consultation. Geneva, Switzerland.

9. Dallman PR, Looker AC, Johnson CL, et al. (1996) Influence of age on laboratory criteria for the diagnosis of iron deficiency anemia and iron deficiency in infants and children. In Iron Nutrition in Health and Disease, pp. 65-74 [L Hallberg and NG Asp, editors]. London: John Libbey \& Company.

10. Gibson RS (1990) Assessment of trace-elements. In Principles of Nutritional Assessment, pp. 511-576 [RS Gibson, editor]. Oxford: Oxford University Press.
11. Abrams SA (1999) Using stable isotopes to assess mineral absorption and utilization by children. Am J Clin Nutr 70, 955-964.

12. Brown E, Hopper J Jr, Hodges JL Jr, et al. (1962) Red cell, plasma and blood volume in healthy women measured by radiochromium cell-labeling and hematocrit. J Clin Invest 41, 2182-2190.

13. Hettiarachchi M, Hilmers D, Liyanage C, et al. (2004) $\mathrm{Na}_{2}$ EDTA enhances the absorption of iron and zinc from fortified rice flour in Sri Lankan children. J Nutr 34, 3031-3036.

14. Peres JM, Bureau F, Neuville D, et al. (2001) Inhibition of zinc absorption by iron depends on the ratio. J Trace Elem Biol 15, $237-241$

15. Davidsson L, Kastenmayer P, Szajewska H, et al. (2000) Iron bioavailability in infants from an infant cereal fortified with ferric pyrophosphate or ferrous fumarate. Am J Clin Nutr 71, 1597-1602.

16. Davidsson L, Dimitriou T, Boy E, et al. (2002) Iron bioavailability from iron-fortified Guatemalan meals based on corn tortillas and black bean paste. Am J Clin Nutr 75, 535-539.

17. Tondeur MC, Schauer CS, Christofides AL, et al. (2004) Determination of iron absorption from intrinsically labeled microencapsulated ferrous fumarate (sprinkles) in infants with different iron and hematologic status by using a dual-stableisotope method. Am J Clin Nutr 80, 1436-1444.

18. Lutter CK \& Rivera J (2003) Nutritional status of infants and young children and characteristics of their diets. J Nutr 133, 2941S-2949S

19. Hurrell R (2003) Influence of vegetable protein sources on trace element and mineral bioavailability. J Nutr 133, 2973S-2977S

20. Crofton RW, Gvozdanovic D, Gvozdanovic S, et al. (1989) Inorganic zinc and the intestinal absorption of ferrous iron. Am J Clin Nutr 50, 141-144.

21. O'Brien KO, Zavaleta N, Caulfield LE, et al. (1999) Influence of prenatal iron and zinc supplements on supplemental iron absorption, red blood cell incorporation, and iron status in pregnant Peruvian women. Am J Clin Nutr 69, 509-515.

22. Rossander-Hulten L, Brune M, Sandstrom B, et al. (1991) Competitive inhibition of iron absorption by manganese and zinc in humans. Am J Clin Nutr 54, 152-156.

23. Friel JK, Serfass RE, Fennessey PV, et al. (1998) Elevated intakes of zinc in infant formulas do not interfere with iron absorption in premature infants. J Pediatr Gastroenterol Nutr 27, 312-316

24. Chiplonkar SA \& Agte VV (2005) Predicting bioavailable zinc from lower phytate forms, folic acid and their interactions with zinc in vegetarian meals. $J$ Am Coll Nutr 25, 26-33.

25. World Health Organization (2002) Global Strategy for Infant and Young Child Feeding, Doc A55/15. Geneva: World Health Organization.

26. Abrams SA \& Atkinson SA (2003) Calcium, magnesium, phosphorus and vitamin D fortification of weaning foods. J Nutr 133, 2994S-2999S.

27. Dalton MA, Sarget JD, O'Connor GT, et al. (1997) Calcium and phosphorus supplementation of iron-fortified infant formula: no effect on iron status of healthy full-term infants. Am J Clin Nutr 65, 921-926.

28. Abrams SA, Griffin IJ, Davila P, et al. (2001) Calcium fortification of breakfast cereal enhances calcium absorption in children without affecting iron absorption. $J$ Pediatr 139, $522-526$.

29. Shah M, Griffin IJ, Lifschitz CH, et al. (2003) Effect of orange juice and apple juices on iron absorption in children. Arch Pediatr Adolesc Med 157, 1232-1236.

30. Etcheverry P, Hawthorne KM, Liang LK, et al. (2006) Effect of beef and soy proteins on the absorption of non-heme iron and inorganic zinc in children. $J$ Am Coll Nutr 25, 34-40. 
31. Lynch MF, Griffin IJ, Hawthorne KM, et al. (2007) Iron absorption is more closely related to iron status than to daily iron intake in 12- to 48-mo-old children. J Nutr 137, 88-92.

32. Bodiga S \& Krishnapillai MN (2007) Concurrent repletion of iron and zinc reduces intestinal oxidative damage in iron- and zinc-deficient rats. World J Gastroenterol 13, 5707-5717.

33. Sreedhar B, Subramaniyan R \& Nair KM (2004) A protective role for zinc on intestinal peroxidative damage during oral iron repletion. Biochem Biophys Res Commun 318, 992-997.

34. Lutter CK \& Dewey KG (2003) Proposed nutrient composition for fortified complementary food. J Nutr 133, 3011S-3020S.

35. World Health Organization (2005) Guidelines on food fortification with micronutrients for the control of micronutrient malnutrition. Geneva: World Health Organization.
36. Murphy SP \& Barr SI (2005) Challenges in using the dietary reference intakes to plan diets for groups. Nutr Rev $\mathbf{6 3}$, $267-271$.

37. World Health Organization (2004) Vitamin and Mineral Requirements in Human Nutrition, 2nd ed. Geneva: World Health Organization/Food and Agriculture Organization.

38. Hettiarachchi M, Liyanage C, Wickremasinghe R, et al. (2006) Prevalence and severity of micronutrient deficiency: a crosssectional study among adolescents in Sri Lanka. Asia Pac $J$ Clin Nutr 15, 56-63.

39. Sparacino G, Shames DM, Vicini P, et al. (2002) Double isotope tracer method for measuring fractional zinc absorption: theoretical analysis. Am J Physiol Endocrinol Metab 282, E679-E687. 